\title{
O CONCEITO DE SOBRECULTURALIDADE E OS IMPASSES RELATIVISTAS ENTRE OS DIREITOS HUMANOS E A EDUCAÇÃO DIFERENCIADA
}

\author{
Daniel Valério Martins ${ }^{1}$
}

\begin{abstract}
Resumo
O presente artigo discute a complexa situação do relativismo cultural dentro das linhas de Direitos Humanos, Antropologia e Educação Diferenciada relacionados à culturas indígenas. $\mathrm{O}$ trabalho dá sugestões para atenuar consequências de certos impasses utilizando o conceito de sobreculturalidade proposto pelo autor deste artigo em sua tese doutoral, como ferramenta utilizada pela Educação Diferenciada, onde passa a ser entendida como o espaço no qual é favorecido o encontro dos diferentes, gerando a identificação e a interação com as diferenças, produzindo ou reproduzindo cultura ou transcultura. Para tanto, faremos um recorrido histórico sobre os Direitos Humanos, relativizando por meio da Educação ao mesmo tempo que mostramos tal processo como elemento de reafirmação cultural e identitária, capaz de manter viva a cultura indígena que vem sendo sufocada e dizimada pela população em seu entorno com seus interesses políticos e econômicos.
\end{abstract}

Palavras-chave: Educação Diferenciada. Direitos Humanos. Cultura. Sobreculturalidade

\begin{abstract}
This article discusses the complex situation of cultural relativism within the lines of Human Rights, Anthropology and Differentiated Education related to indigenous cultures. The work promotes suggestions to mitigate consequences of certain impasses using the concept of overculturality proposed by the author of this article in his doctoral thesis, as a tool used by Differentiated Education, where it is understood as the space in which the meeting of the different is favored, generating the identification and interaction with differences, producing or reproducing culture or transculture. To this end, we will make a historical tour on Human Rights, relativizing through Education at the same time that we show this process as an element of cultural and identity reaffirmation, capable of keeping alive the indigenous culture that has been suffocated and decimated by the population in its surroundings with their political and economic interests.
\end{abstract}

Keywords: Differentiated Education. Human rights. Culture. Overculturality

\footnotetext{
${ }^{1}$ Daniel Valério Martins, Doutor em Antropologia pela Universidade de Salamanca - USAL na Espanha, Doutor em Educação pela Universidade de Burgos - UBU na Espanha e Pós-Doutor pelo Instituto Histórico Geográfico de Santa Catarina - IHGSC. E-mail jifadelino@ hotmail.com e ORCID: 0000-0003-0777-9750
} 


\section{Introdução}

Iniciamos nossas reflexões sobre os direitos humanos, observando seu surgimento no ano de 1948 com a Declaração Universal dos Direitos Humanos, com o objetivo de fazer com que os 184 países que a assinaram, asumissem compromissos de investimentos na humanização dos povos como um bem comum a ser alcançado. Apesar de este haver sido o primeiro fato oficial sobre o tema, sabemos que os direitos humanos possuem raízes mais remotas, podendose citar a própria Revolução Francesa de 1789 com seu lema de liberdade, igualdade e fraternidade. Se analisarmos de uma forma mais profunda, podemos, ainda, mencionar raízes anteriores, como, por exemplo, quando René Descartes pronunciou, no século XVII, a sua emblemática frase "penso, logo existo", situando o homem e sua existência como o centro da ciência e da política, ou seja, o centro da sociedade - homem este que é a base de estudo da Antropologia.

Na Espanha, o Fray Bartolomé de las Casas ${ }^{2}$ e Francisco de Vitoria apresentam-se nas obras de García (2003) como personalidades ligadas à teoría e prática dos direitos humanos. Foram grandes defensores dos indígenas que consideravampovos "oprimidos", havendo lutado por seus direitos como seres humanos, racionais e livres. O objetivo era promover-lhes a dignidade, liberdade e justiça, na busca por preservar suas culturas, suas terras e seus bens. Bartolomé de Las Casas, particularmente em seus estudos da antropologia filosófica e caracterização dos direitos naturais do ser humano, teria formulado, na época, o que posteriormente se desenvolveria como direitos humanos.

\section{$1 \mathrm{O}$ Relativismo Cultural como desafio às práticas de direitos humanos}

A antropologia é o estudo do homem com base em sua cultura. Quando pensamos em direitos humanos, temos a idéia do princípio da "humanidade", logo entendemos que o direito à vida é soberano. $\mathrm{O}$ que se pretende trazer à reflexão, ao longo deste tópico, são as possíveis discrepâncias ou consensos de determinados conceitos, quando trabalhamos lado a lado com a antropologia e os direitos humanos. Isto porque, em alguns momentos, a cultura do indivíduo

\footnotetext{
${ }^{2}$ Bartolomé de Las Casas (1484-1566), fraile dominico español, cronista, historiador, filósofo, teólogo, jurista, obispo de Chiapas, es reconocido como el gran defensor de los indígenas americanos. Nació en Sevilla, donde cursó estudios de latín y humanidades. El curriculum de la época era el trilingüe (latín, griego y hebreo), el trivium, (gramática, retórica y dialéctica) y el cuatrivium (aritmética, geometría, astronomía y música). A los nueve años, el 31 de marzo de 1493, vivió un suceso memorable: el regreso a Sevilla de Colón que volvía del descubrimiento de América con "gran alarde de indígenas, loros ypapagayos". Meses después, el 25 de septiembre, su padre, Pedro de las Casas y el tío, Francisco de Peñalosa, embarcaron en el segundo viaje de Colón. En 1494, regresó su padre con un indio taíno esclavo, que estuvo con Bartolomé hasta 1500 cuando, por orden de Isabel la Católica, fue devuelto a América, junto con los otros indios traídos a España (García, 2003).
} 
entra em choque com o direito à vida. Desta maneira, é preciso analisar os "sentimentos" dos indivíduos estudados de maneira participativa, a fim de que se tenha uma idéia real e uma solução pertinente ao problema enfrentado. Este impasse referente ao relativismo cultural é encontrado frequentemente quando nos deparamos com culturas indígenas. Ou seja, o que devemos priorizar? O princípio humanista ou o princípio cultural desses povos?

Ao afirmar que "sou homem e depois sou cultura", com a idéia de que o ser humano vem antes de sua cultura, o homem, objeto dos direitos humanos, pode entrar em contradição com o entendimento de que "sou considerado humano, porque tenho uma cultura". Diante do exposto, entramos em uma discusão já debatida entre a antropologia e os direitos humanos, buscando-se suporte teórico no relativismo cultural de Franz Boas, segundo o qual devemos observar os sistemas culturais sem a utilização de parâmetros preestabelecidos, preconcebidos, sem "pré-conceitos", de modo a nos distanciar de uma visão etnocêntrica, sendo necessário observar os padrões culturais desde a sociedade que os criou.

Por um lado, sabemos o quanto etnocêntrico é a expressão "direitos humanos" com suas pretensões hegemônicas inerentes a formações culturais específicas, ancoradas em instituições, estados e demais aparatos de poder. Por outro lado, embora inserida nesta mesma história que se vê como universal, a tradição disciplinar antropológica nos legou como herança a possibilidade de questionar preconceitos e ver os "direitos" dos outros. É por este ângulo que podemos reconhecer hoje no interior do campo dos "Diretos Humanos" instrumentos valiosos para a reafirmação do valor da diversidade cultural, para o questionamento das desigualdades sociais, para a defesa dos valores democráticos. (NOVAES; LIMA, 2001. p. 9).

O relativismo cultural utilizaria, portanto, um elemento chave para a análise funcional, que é a observação participante durante o trabalho etnográfico, dentro de uma cultura nativa, por meio da imersão, para compreender o seu funcionamento com base em sua história e estrutura, conforme explica Malinowski (1922), em sua obra "Os argonautas do Pacífico Ocidental".

Nesse ponto, verifica-se que muitos teóricos contrapõem esse princípio do relativismo cultural ao princípio dos direitos humanos, não obstante, há que se ter em mente que o relativismo cultural não parte do indício de que toda expressão cultural seja correta, já que, muitas vezes, observamos padrões culturais e tradições que possam denegrir fisica, mental e socialmente a dignidade de um ser humano, entendendo que essa expressão é passível de respeito, mas, à medida que é aberta ao diálogo, é portanto, também relativa.

Esteva (1998) aborda a temática dos direitos humanos como uma medida etnocêntrica capaz de gerar uma recolonização ocidental de todos os que não aceitam suas ideias universalistas. Não obstante, ao se observarem a causa e o ressurgimento do movimento 
indigenista, deparamo-nos com a seguinte indagação: o que seria das comunidades indígenas que se fortaleceram e estão conseguindo mostrar ao mundo suas lutas e reafirmação identitária com a apropriação dos Direitos Humanos? (RAMOS, 1999).

O autor Rosinaldo Silva Sousa afirma que a maneira como é trabalhada a igualdade entre os homens pelos princípios dos direitos humanos tem uma base totalmente etnocêntrica; senão, veja-se:

É justamente partindo do reconhecimento da diferença como constituinte de uma subjetividade inalienável dos sujeitos sociais que a antropologia pode contribuir para a elaboração de contra discursos, capazes de se contrapor ao discurso universalista ocidental. (SOUSA, 2001 in TAVARES, 2010, p. 4898).

Partindo desse princípio, a causa indígena torna-se um elo entre a antropologia e o relativismo cultural, dado que ela toma por base a diferença, garantindo-se, ainda, os direitos humanos desses povos, os quais são efetivados por meio da divulgação ao mundo de suas lutas por reafirmação identitária.

Una corriente importante de la concepción antropológica se expresa en el relativismo cultural. No se da una apreciación de hombres o pueblos "cultos" o "incultos"; no hay culturas "mejores", ni "peores"; ni "inferiores" o "superiores". Hay culturas diferentes. Sin embargo, este relativismo cultural no lleva a un relativismo ético que no es aceptable para la convivencia humana. No todo vale, ni se puede eludir la responsabilidad moral de cada ser humano $[\ldots]$ tiene una responsabilidad para algo; ese algo es el bienestar y la dignidad del otro.

Todas las formas de existencia humana, cualquiera sea su grado de desarrollo, expresan formas de cultura que son diferentes respuestas al problema de la vida. (ANDER-EGG, 2009, p.97).

A busca pelo consenso entre as diferenças no âmbito cultural e entre as ideias da antropologia e dos teóricos dos direitos humanos surge, nesse contexto, com as ferramentas da ética e da educação - uma educação diferenciada, capaz de pregar a igualdade entre os homens, por meio de seus direitos e deveres, respeitando-se as diferenças culturais, que são a base de fundamentação da Antropologia.

Constrói-se, assim, um cenário propício para a aplicação do conceito de sobreculturalidade ${ }^{3}$ como elemento equalizador aplicado no contexto educacional de base, para o fortalecimento e crescimento pessoal e coletivo, com base no autorreconhecimento e na autoaceitação, no conhecimento sobre o outro e o respeito mútuo, para que enfim se dê lugar a uma convivência pacífica. Esta, então, se tornará o palco para o enriquecimento cultural por meio do contato, fazendo surgir, desse modo, um indivíduo capaz de conviver e respeitar todo

\footnotetext{
${ }^{3}$ Sobreculturalidade trata-se do processo de sobrevivência cultural que versa sobre fases de contato quando o mesmo se torna inevitável. As fases são as seguintes: Intra, Multi, Inter e Transculturalidade. Tal conceito foi desenvolvido pelo autor desse artigo em sua tese doutoral, realizando trabalhos etnográficos na Bolívia, no México, na República Dominicana e no Brasil.
} 
o contexto multicultural, global e universal do qual faz parte. (MARTINS, 2016). Para tanto elaboramos o seguinte esquema estrutural:

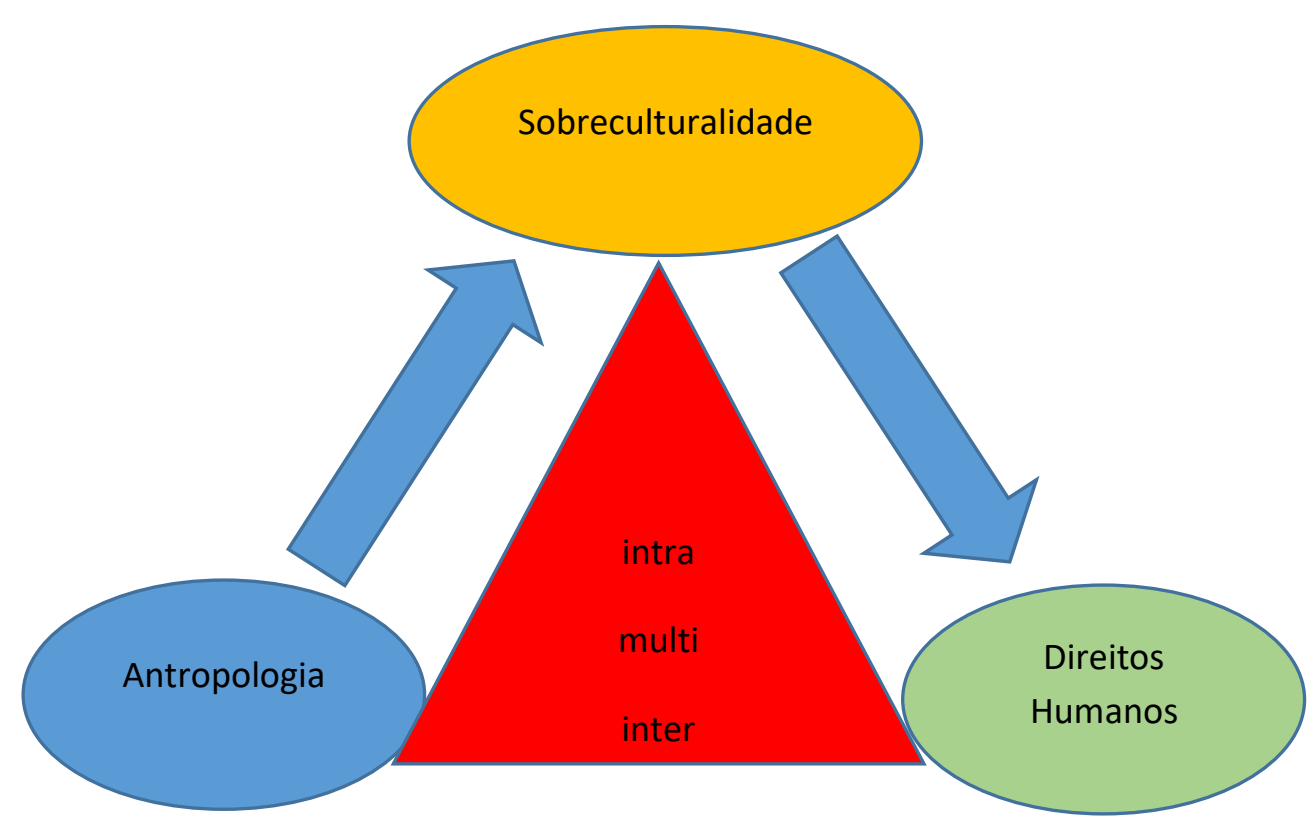

Fonte: Elaboração própria (MARTINS, 2016).

Figura 1 - Esquema estrutural conceitual

Partindo desse ponto de vista, o processo de sobreculturalidade pode ser entendido como um dos pontos de equilíbrio entre a discussão da Antropologia com os Direitos Humanos, quando trabalhada na busca por uma convivência pacífica com o contato cultural, abordando conceitos antropológicos e ao mesmo tempo promovendo os Direitos Humanos e a luta pela aplicação dos mesmos por meio de uma educação diferenciada, utilizando como exemplo a questão indígena.

\section{0 processo de Sobreculturalidade na promoção dos Direitos Humanos}

O processo de sobreculturalidade consiste em explicar a transformação, gerada com o contato, pois é observada em todos os códigos de conduta, os valores morais, as regras sociais e culturais, como a própria língua e a educação, que são as bases de orientação de qualquer indivíduo no mundo. Assim, o processo sobrecultural, enquanto depende da relação de um indivíduo consigo mesmo e com os outros sob forma de autoaceitação, encontro, conflitos e interação, gera uma problemática cultural e, por isso, muda ou se transforma por resiliência, adequação, adaptação e sobrevivência. Nesse momento, entendemos o processo sobrecultural 
Cadernos CERU, Série 2, Vol. 31, n. 1, jun. 2020

como uma situação de ajuste social de um indivíduo com o grupo ao que pertence e, ao mesmo tempo, com os grupos no seu entorno, não se tratando de um processo meramente aculturador, no pensamento de Schaden (1969), e sim somador de várias culturas, a fim de tornar o indivíduo conhecedor de várias realidades, para perceber que a cultura é viva e, portanto, mutável.

Sendo assim, o conceito de sobreculturalidade, enquanto "cultura de sobrevivência", foi direcionado às culturas que foram obrigadas a passar pelas várias etapas do processo de contato cultural para sobreviverem, não caírem no esquecimento e seguirem lutando na tentativa de garantir as diferenças.

Apesar do contexto de luta pela diferença, expressada na diversidade cultural brasileira e universal, na qual os indígenas estão inseridos, o artigo $1^{\circ}$ da Declaracão Universal dos Direitos Humanos de 1948 estabelece que "todos os seres humanos nascem livres e iguais, em dignidade e direitos, devendo comportar-se fraternalmente uns com os outros”. E o artigo $2^{\circ}$ é muito claro ao taxar que essa "liberdade não estabelece distinção de raça, cor, sexo, idioma, religião, opinião política ou qualquer outra índole”.

Vimos que, entre as lutas indígenas, está inserida a luta por suas terras e territórios, identificada como parte de sua cultura e, portanto, de sua vida. De outra banda, o Artigo 13 da Declaração supramencionada estabelece que toda pessoa tem o direito de circular livremente no território de um Estado e escolher sua residência nesse território e o artigo 15 estabelece o direito de escolher e pertencer a uma nacionalidade.

Dessa forma, no caso das comunidades indígenas PITAKAJÁ4, entra em cena o processo de sobreculturalidade por meio de ferramentas como a educacão, na tentativa de se formarem indígenas capazes de serem sujeitos ativos na sociedade, capazes de adquirir voz ativa na política. Aqui, também podemos citar o Estado Plurinacional da Bolívia, com suas trinta e sete nacões de povos originários, fazendo valer a efetivacão de parte dos Direitos Humanos, respeitando-se seu espaço, ou seja, suas terras e territórios, como estados interdependentes.

Como bem expressa o Artigo 28 da Declaracão Universal dos Direitos Humanos, "todo indivíduo tem o direito e a liberdade de buscar a efetivacão desses direitos”. Assim, podemos considerar que o processo de Sobreculturalidade aspira estabelecer uma ordem social, uma vez que tenta fortalecer o individuo, com todas suas etapas anteriormente expostas e propostas.

\footnotetext{
${ }^{4}$ O termo PITAKAJÁ faz referência a cinco comunidades indígenas do Ceará, Pitaguary, Tapeba, Kanindé, Jenipapo- Kanindé e Anacé, que se juntaram em um processo de educação superior para a formação de professores indígenas.
} 
Cadernos CERU, Série 2, Vol. 31, n. 1, jun. 2020

Assim, em alguns pontos, vemos convergir algumas caracterisitcas da Antropologia e dos Direitos Humanos que a princípio se mostram incompativeis, como expressado no trecho abaixo:

Se nos remetermos à Convenção 169, de 1989, da Organização Internacional do Trabalho (OIT) sobre Povos Indígenas e Tribais em Países Independentes, ratificada pelo Brasil em junho de 2002, seremos advertidos de que, embora se recomende sensibilidade com relação ao chamado direito "consuetudinário" e aos costumes das sociedades indígenas, esses outros direitos, ou direitos próprios, tal como às vezes são denominados, não podem ser contraditórios com os direitos definidos pelo sistema jurídico nacional nem com os direitos humanos internacionalmente reconhecidos. Mantém-se, assim, certo grau de indefinição, ao se inovar no pluralismo que a Convenção introduz, insistindo-se, contudo, na necessidade de negociar quando as leis modernas e em especial os direitos humanos instituírem o caráter intolerável de determinados costumes. (SEGATO, 2006, p.208).

Tal discussão veio à tona durante uma reunião em Brasilia, na qual quarenta e uma mulheres indigenas debatiam durante uma semana sobre a participação na Oficina de Capacitação e Discussão sobre Direitos Humanos, Gênero e Políticas Públicas. Após, a FUNAI iria elaborar uma cartilha para a aplicação dos conhecimentos em comunidades indígenas.

Um dos momentos mais ricos e complexos da discussão de conceitos ocorreu quando uma das participantes, a advogada indígena Lúcia Fernanda Belfort kaigang, perguntou sobre a possibilidade de se considerar o costume tradicional de um povo originário equivalente à lei, ou seja, sobre a possibilidade de se considerar o direito "tradicional", o costume, equivalente ao direito em seu sentido moderno e passível de substituição dentro da comunidade. Esta é, sem dúvida, uma grande pergunta, que encontra as respostas mais diversas na literatura sobre o tema. (SEGATO, 2006, p. 208).

\section{A aplicação do processo de sobreculturalidade e o exemplo dominicano}

Para a aplicação do conceito de sobreculturalidade e vislumbrar a sua relação com os direitos humanos, temos que levar em consideração vários elementos que seriam responsáveis por sua efetivação, dentre eles, destacamos ferramentas pedagógicas como a educação, capaz de mostrar as várias visões e sob vários pontos de vista, as ideias e valores comuns a todos os seres humanos. Dessa forma, o consenso gerado por meio da educação, nesse caso, a diferenciada, com base intercultural, seria o elo entre a sobreculturalidade e os direitos humanos, podendo surgir, aqui, outra triangulação conceitual que será desenvolvida em futuras investigações: sobreculturalidade - educação - direitos humanos.

Partindo-se desse ponto de vista, o processo de sobreculturalidade, com todas as suas fases ou etapas, seria utilizado como preparação do indivíduo para uma educação diferenciada com base intercultural voltada para os direitos humanos. Isto porque o indíviduo, ao entrar em contato com outras culturas, podendo distinguir e estabelecer as diferenças entre o "eu" e o 
Cadernos CERU, Série 2, Vol. 31, n. 1, jun. 2020

"outro", passa a se fortalecer culturalmente, aceitando sua identidade (diferente), além de reconhecer no outro essas diferenças, passando a respeitar e tolerar as divergências e pontos de vista, em busca de uma interação no intuito de enriquecimento mútuo, gerando uma transformação ou uma transcultura como resultado desse contato. A educação diferenciada mostra-se, portanto, como o ambiente propício para a busca pela efetivação dos Direitos Humanos, em especial a dignidade humana.

Remetendo-nos a Calvo (2003), podemos entender cada fase ou etapa do processo de sobreculturalidade e sua relação com os direitos humanos, quando esse autor afirma que as identidades geográficas, ideológicas, étnicas e religiosas são positivas, humanizadoras e funcionais, pois não podemos ser cidadãos do mundo se não nos sentimos cidadãos de alguma parte, devendo as identidades constituir círculos abertos, que não excluam o sentimento de identificação, integração ou pertencimento a outros grupos.

As etapas do processo de sobreculturalidade se veem embutidas no pensamento de Calvo (2003), no ponto em que ele faz um resumo sobre o multiculturalismo como um bem enriquecedor para uma sociedade, quando os indivíduos, reciprocamente, sabem dialogar de forma intercultural, respeitando valores e normas mínimas de convivência, como os próprios Direitos Humanos e as leis constitucionais, num contexto de uma aldeia global interrelacionada pelos meios de comunicação, caracterizada pela integração, o universalismo e a globalização.

Portanto, a fim de se concretizar uma educação voltada para os Direitos Humanos, o papel da ideia de sobreculturalidade seria preparar as bases que permitam a autoaceitação. As etapas do processo foram citadas por Calvo (2003), em outras palavras, quando ele diz que o indivíduo, na busca por um enriquecimento mútuo por meio do contato, fortalece-se com o sentimento de pertencimento a um grupo específico, portanto, diferente (intra), buscando no contato com o outro (multi), por meio do diálogo, respeito, tolerância e interação (inter), valores comuns a todos, que são gerados por meio de uma transformação por meio do processo educativo. Na mesma esteira, vale remetermo-nos a Espina (2003), o qual afirma que a cultura não está unitariamente construída, mas, pelo contrário, é um campo aberto a modificações, à criatividade e à identidade múltipla.

Tudo o que foi anteriormente exposto pode ser exemplificado na busca pelo conhecimento de outras culturas, em que os indivíduos saem de seus grupos de origem para obter novos conhecimentos no contato com outras realidades (caso de investigações, intercâmbios, imersão cutural etc.), de modo a passar por todas as etapas do processo de sobreculturalidade, pois, ao princípio desse afastamento de sua própria cultura, aflora um 
sentimento identitário, ao se compararem as realidades, sentindo-se falta de suas tradições, amigos, culinária, família, comportamentos etc. Nesse ponto, ocorrem várias interculturalidades dentro do contexto multicultural, por meio da interação, na tentativa de adquirir padrões culturais que venham a transformar realidades, voltadas para a ética, valores morais e humanos, que cada vez mais se desumanizam com a banalização da violência, corrupção e vários outros problemas derivados.

Portanto, existe uma relação estreita e não muito contemplada entre a Antropologia e os Direitos Humanos e, nesse caso específico, por meio de ferramentas como a educação intercultural e diferenciada, que utilizaria, na busca pelo consenso, a aplicação do conceito de sobreculturalidade.

Tal aplicação é justificada em todo este artigo, havendo a pretensão de futuras investigações que, a priori, poderíamos adiantar nosso desejo em tratá-la em perspectiva comparada com mais um grupo indígena, os Tainos da República Dominicana, que muitos estudiosos consideram extintos e que estudos recentes mostraram o contrário, havendo sido eles os primeros indígenas a se tornarem objeto de discussão na base dos direitos humanos por Bartolomé de Las Casas, nos séculos XV e XVI. Veja-se que, apesar de não haver comunidades indígenas na República Dominicana, a cultura Taina segue viva na culinária, nos nomes de lugares e nos traços físicos característicos, inclusive estudos recentes mostram que mais de $15 \%$ da população possuem DNA puramente taino. ${ }^{5}$

O Instituto Dominicano de Desarrollo Integral - IDDI, no qual foi realizada uma estância de cooperação internacional durante o ano de 2015, desenvolve um projeto denominado EPC, Espacio Para Crecer, dentre os programas do projetomacro Alerta Jovem, financiado pela USAID - Agência dos Estados Unidos para o Desenvolvimento Internacional, apresentando, em seu material didático, a utiização do método Quantum learning $^{6}$, de modo que no tempo extra classe, são ministrados pelos facilitadores módulos direcionados às crianças com problemas de aprendizagem, fora da faixa etária padrão e procedentes de famílias conflitivas, com as seguintes temáticas:

\footnotetext{
${ }^{5}$ Um grupo de investigadores da Universidade de Porto Rico e da Universidade Central del Leste realizou uma pesquisa com base em provas de DNA mitocondrial cujos resultados preliminares permitem sugerir que entre 15 e $18 \%$ da população dominicana tem ascendência taina direta, por linhagem materna. Mais informações disponíveis em: https://miches.wordpress.com/2008/10/08/dominicanos-con-ascendencia-genetica-de-origentaino/.

${ }^{6}$ Quantum Learning não é nada mais que um conjunto de conhecimentos, princípios e métodos que facilitam a aceleração da apredizagem, a fim de que ela seja mais relevante e significativa, método criado por Georgi Lozanov, que também o chamava de Superaprendizagem.
} 
- Yo soy especial

- Mi familia, mi comunidad más cercana

- El ambiente que me rodea

- Cuido de mi salud

- Qué orgullo ser Dominicano!

Todos esses módulos apresentam características nas quais vemos que podem ser aplicadas todas as etapas do processo de sobreculturalidade, uma vez que objetivam o respeito à diversidade, na medida em que se observam constantes conflitos entre dominicanos e haitianos, que coabitam a mesma ilha, ademais de todas as culturas que formaram o povo dominicano. Assim, tal metodologia consiste em trabalhar oito chaves para se chegar à excelência. Estas são introduzidas da seguinte forma: o indivíduo, ao rever seus valores e ações, portanto, sua integridade, passa a entender seus equívocos, podendo refletir sobre eles na tentativa de mudança, passando a falar com mais clareza suas boas intenções e, nesse momento, dar-se conta de que é necessário pôr em prática ações com mais compromisso com sua família, apropriando-se dos ensinamentos adquiridos frente ao problema enfrentado, buscando flexibilizar, em suas palavras, suas ações, por meio do respeito e aceitação, com o fim último de pôr em balanço os valores da família (sua primeira comunidade) e o seu entorno.

\section{Considerações Finais}

Feita essa breve explanação sobre outro projeto que posteriormente será estudado com mais afinco, a proposta aqui apresentada, como já dito e redito, é a busca pela aplicação do conceito de sobreculturalidade que, além dos demais conceitos abordados nas fases do seu processo, se utilizaria de ferramentas pedagógicas, como a educação inicial intercultural, de base e diferenciada, com uma metodologia específica, aproximando-se da metodologia Quantum Learning, utilizada na República Dominicana com a finalidade de preparar as crianças para o respeito e a aceitação da diversidade, palavras-chave quando se fala em Direitos Humanos. Deste modo, se faz valer a seguinte triangulação: Sobreculturalidade - Educação Diferenciada - Direitos Humanos, a fim de que, quiçá, possamos contribuir para uma parcela da sociedade que, infelizmente, a cada dia, vem sendo desumanizada.

Sobre essa questão, disserta Aparício (2011):

Aún existe discriminación y desprecio respecto al caudal cultural de los pueblos originarios; lo que se traduce a vulneración de derechos, falta de pertinencia al momento de tratar contenidos concernientes a dichas culturas y de promoción del conocimiento y ejercicio de sus derechos. (APARÍCIO, 2011, p.67). 
E assim, nessa esfera, conjugando com Aparício encontramos em Schaden as sementes para o que chamamos neste artigo, de processo de sobreculturalidade, quando nos mostra no processo de aculturação (a mesma que pode trazer a vulnerabilidade) uma divisão em etapas apresentando a seguinte ordem: a) transmissão intercultural (difusão), b) criatividade cultural, c) desitegração cultural, d) reações adaptativas (SCHADEN, 1976).

Mesmo o autor trabalhando conceitos observados na década de 50, valemo-nos de sua lógica quando nos diz que "as instituições primitivas não são apenas capazes de conservar o que existe, ou de reter provisoriamente os vestígios de um passado que se desfaz, mas também de elaborar inovações audaciosas, ainda que as estruturas tradicionais com isso se tranformem profundamente". (SCHADEN, 1976).

A utilização do conceito de sobreculturalidade e sua respectiva aplicação mostram-se, portanto, como o ponto primordial para a inter-relação dos elementos educação, antropologia e direitos humanos, figurando como efetiva ferramenta para a junção prática dos conceitos abrangidos pelo processo dentro de uma educação diferenciada.

\section{Referências bibliográficas}

ANDER-EGG, E. Aproximaciones al problema de la cultura, como respuesta al problema de la vida. Buenos Aires- México: Lumen Hymanitas, 2009.

APARÍCIO, J. M. Didáctica de las Ciencias Sociales: cuatro casos prácticos. in: M. M. Guerrero (Coord.). Valladolid: Ediciones Seminario Iberoamericano de Descubrimientos e Cartografía, 2012.

APARÍCIO, J. M. Interculturalidad, Educación y Plurilinguismo en América Latina. Madrid: Pirámide, 2011.

APARÍCIO, J.M.; DELGADO, M. A. La Educación Intercultural en la Formación Universitaria Europea y Latinoamericana. Segóvia: ITAMUT- FIFIED, 2014.

AUGÉ, M. O Antropólogo e o mundo global. Petrópolis: Vozes, 2014.

CALVO, T. B. Inmigración y multiculturalismo: ¿gangrena de la sociedad o enriquecimiento mutuo? in: A. B. Bárrio, Antropologian Castilla y León e Iberoamerica, V. Emigración e Integración cultural (p. 30-51). Salamanca: Ediciones Universidad de Salamanca, 2003.

ESPINA, Á. B. Antropología en Castilla y León e Iberoamérica, V. Emigración e Integración Cultural. Salamanca: Ediciones Universidad de Salamanca, 2003.

ESTEVA, G. Autonomía y democracia radical: el tránsito de la tolerancia a la hospitalidad. in: M. A. Barabas, Autonomías éticas y Conaculta - INAH, 1998.

FLEURI, R. M. O que significa Educação Intercultural. in: Educação para a diversidade e cidadania. Florianópolis: Mover, NUP, 2009.

GARCÍA, E. G. Bartolomé de las Casas y los Derechos Humanos. in: M. M. Mendez, Los derechos humanos en su origen. La República Dominicana y Antón de Montesinos (p. 81-114). Salamanca: San Esteban, 2003. 
Cadernos CERU, Série 2, Vol. 31, n. 1, jun. 2020

GARCÍA, G. A. El hombre. Salamanca: Sígueme, 2009.

MALINOWSKI, B. Argonautas do Pacífico Ocidental: um relato do empreendimento e da aventura dos nativosnos arquipelágos da Nova Guiné melanésia. São Paulo: Abril Cultural, 1976.

MARTINS, D. V. A intraculturalidade nas comunidades indigenas da Região Metropolitana de Fortaleza - Ce - Brasil: Caminho para o desenvolvimento e sobreculturalidade. Salamanca: Ediciones Vitor, 2016.

NOVAES, R. R.; LIMA, R. K. Antropologia e Direitos Humanos. Niterói: Eduff, 2001.

POZZER, A. Educação e Interculturalidade: conhecimentos, saberes e práticas descoloniais. Blumenau: Edifurb, 2014.

RAMOS, A. R. Cutting through state and class sources. Austin: University of Texas Press, 1999.

SCHADEN, E. Aculturação indígena. São Paulo: EDUSP, 1969.

SCHADEN, E. Leituras de Etnologia Brasileira. São Paulo: Companhia Editora Nacional, 1976.

SEGATO, R. L. Antropologia e Direitos Humanos, Alteridade e ética no movimento de expansão dos direitos universais. Brasília: Mana, 2006.

SOUSA, R. S. Direitos humanos através da história recente em uma perspectiva antropológica. In: R. R. Novaes; R. K. Lima, Antropologia e Direitos Humanos (p. 47-61). Niterói: Eduff, 2001.

TAVARES, F.C. Direitos humanos e diversidade cultural: a dignidade humana entre o universalismo e o relativismo. Fortaleza: CONPEDI, 2010. 